\title{
\begin{tabular}{l|l} 
Mitraries & DSpace@MIT
\end{tabular}
}

\author{
MIT Open Access Articles
}

Modeling Dynamic Ankle Mechanical Impedance in Relaxed Muscle

The MIT Faculty has made this article openly available. Please share how this access benefits you. Your story matters.

Citation: Lee, Hyunglae, and Neville Hogan. “Modeling Dynamic Ankle Mechanical Impedance in Relaxed Muscle." ASME 2011 Dynamic Systems and Control Conference and Bath/ASME Symposium on Fluid Power and Motion Control, Volume 2 (2011).

As Published: http://dx.doi.org/10.1115/DSCC2011-5976

Publisher: ASME International

Persistent URL: http://hdl.handle.net/1721.1/119386

Version: Final published version: final published article, as it appeared in a journal, conference proceedings, or other formally published context

Terms of Use: Article is made available in accordance with the publisher's policy and may be subject to US copyright law. Please refer to the publisher's site for terms of use. 


\section{MODELING DYNAMIC ANKLE MECHANICAL IMPEDANCE IN RELAXED MUSCLE}

\author{
Hyunglae Lee ${ }^{1}$ \\ hyunglae@mit.edu
}

\author{
Neville Hogan ${ }^{1,2}$ \\ $\underline{\text { neville@mit.edu }}$
}

\footnotetext{
${ }^{1}$ Department of Mechanical Engineering, Massachusetts Institute of Technology, Cambridge MA02139

${ }^{2}$ Department of Brain and Cognitive Sciences, Massachusetts Institute of Technology, Cambridge, MA02139
}

\begin{abstract}
This paper presents identification and modeling of dynamic ankle mechanical impedance in relaxed muscles. A multivariable estimation method using a wearable therapeutic robot enabled clear interpretation of dynamic ankle impedance both in the sagittal and frontal planes. Estimation results showed that dynamic ankle behavior apparently cannot be reconciled with a simple $2^{\text {nd }}$ order model. Measurements in a seated and standing position verified that ankle impedance changes substantially depending on lower-limb posture. Identification results were fitted with a modified Hill model with a mass between the muscle and tendon elements. When coupled with foot inertia, either singly or antagonistically, this model successfully captured the dynamic behavior of the ankle impedance both in the seated and standing positions up to 20 $\mathrm{Hz}$. At least a $4^{\text {th }}$ order model having 2 complex zero and 1 complex pole pairs was required to describe relaxed ankle impedance either in the sagittal or frontal plane up to $20 \mathrm{~Hz}$. In the seated position, a $6^{\text {th }}$ order model was slightly better than the $4^{\text {th }}$ order model but with the expense of complexity, and a $8^{\text {th }}$ order model might be used to describe dynamic ankle behavior up to $30 \sim 40 \mathrm{~Hz}$.
\end{abstract}

\section{INTRODUCTION}

The role of the ankle in lower extremity function is perhaps the most important of all joints in the kinematic chain between foot and trunk [1]. Thus a quantitative mathematical model of the ankle may provide valuable information to understand the contribution of the ankle to human locomotion. There has been a great deal of work on the ankle geometry and kinematics [25]. However, functions such as walking, balancing, and coordination are dynamic processes, thus an accurate dynamic model of the ankle, more specifically dynamic ankle mechanical impedance, will enable better interpretation of the roles of the ankle in its interaction with the environment. Ankle mechanical impedance is an operator that maps a time history of displacement of the ankle joint onto a corresponding force time history, which is sometimes called dynamic stiffness or dynamic compliance. Gottlieb and Agarwal [6] measured the dynamic compliance of the normal human ankle joint by applying band-limited Gaussian torques. A similar system identification method was used by Kearney and Hunter [7, 8] and Weiss et al., $[9,10]$ to identify passive and active ankle dynamic stiffness. While most studies only focused on ankle motion in the sagittal plane, Zinder et al., [11] measured inversion/eversion ankle stiffness using a medial/lateral swaying cradle. All these studies modeled ankle mechanical impedance as a $2^{\text {nd }}$ order underdamped system having inertial, viscous, and elastic terms. In contrast, Rastgaar et al., [12], showed that ankle behavior in the sagittal plane cannot be reconciled with a simple $2^{\text {nd }}$ order model. In this study, we extended that work with a more accurate estimation procedure, and present a model of relaxed ankle mechanical impedance both in the sagittal plane (dorsiflexion- plantarflexion (DP) motion) and the frontal plane (inversion- eversion (IE) motion).

\section{EXPERIMENTS}

To characterize ankle mechanical impedance, we utilized a wearable therapeutic robot called Anklebot (Interactive Motion Technologies, Inc.) [13], which applies torque perturbations in 2 degrees of freedom (DOF), and measures displacements. Subjects wore a modified shoe and a knee brace, to which the robot was connected. To study the effect of lower limb posture on ankle impedance, it was measured in two different body postures with the sole at a right angle to the tibia in both cases (Fig.1). 

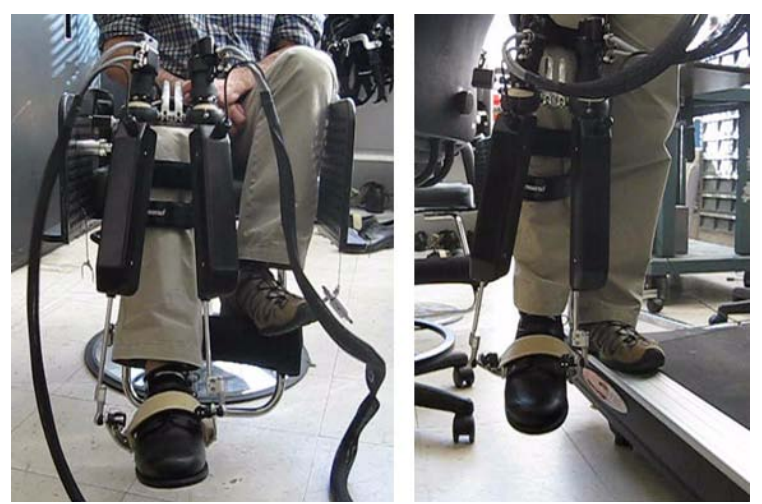

Fig.1. Ankle impedance measurement in two different postures: seated (left) and standing (right) with the ankle clear of the ground

Each measurement lasted for 1 minute, and two measurements were performed for each posture. Subjects were instructed to fully relax while the robot applied random perturbations to the ankle. To monitor whether subjects were fully relaxed, electromyographic (EMG) signals were recorded throughout the procedure. Surface EMG electrodes were placed on 4 major muscles that contribute to ankle movements: tibialis anterior, soleus, gastrocnemius, and peroneus longus. Applied forces, resulting linear displacements of two actuators, and EMG signals were recorded at $200 \mathrm{~Hz}$.

Six unimpaired young male subjects (mid 20's mid 30's) with no reported history of biomechanical or neuromuscular disorders were recruited for this study. Participants gave written informed consent to participate as approved by MIT's Committee on the Use of Humans as Experimental Subjects.

\section{ANKLE IMPEDANCE IDENTIFICATION METHOD}

A linear model of the Anklebot actuator dynamics coupled with the human ankle in actuator coordinates is shown in (Fig.2). To avoid drift exceeding the limited travel length of the actuator and to maintain a mean ankle posture, a position controller with non-zero stiffness value was included.

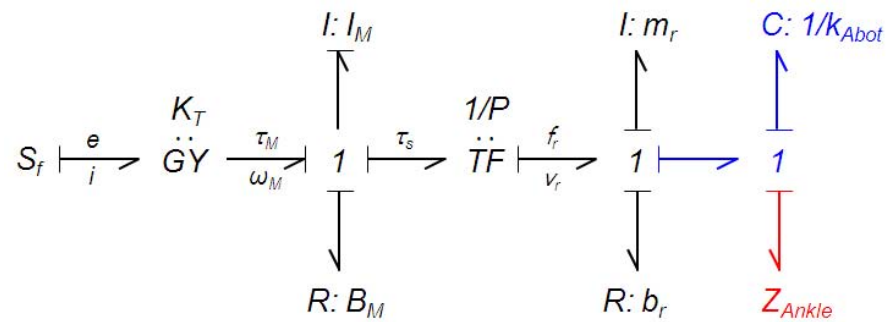

Fig.2. A model of the Anklebot actuator when coupled with the human ankle. ( $i$ : motor current, $\mathrm{K}_{\mathrm{T}}$ : Torque sensitivity, $\mathrm{M}$ : Command torque, s: Motor output torque, м: Motor angular velocity, $I_{M}, B_{M}$ : Motor inertia and damping, $P$ : Linear drive pitch $[\mathrm{rad} / \mathrm{m}], f_{r}$ : Actuator output force, $v_{r}$ : Rod velocity, $m_{r}, b_{r}$ : Linear drive $\&$ rod equivalent mass and damping, $k_{A b o t}$ : Anklebot stiffness from position gain $(500 \mathrm{~N} / \mathrm{m}))$

Without the human ankle the equivalent behavior seen from the actuator output rod is shown in eq. (1), and the impedance of the Anklebot actuator $\left(Z_{\text {Abot }}\right)$ was represented as a $2^{\text {nd }}$ order system in eq. (2).

$$
\begin{aligned}
& \left(m_{r}+P^{2} I_{M}\right) \ddot{x}_{r}+\left(b_{r}+P^{2} B_{M}\right) \dot{x_{r}}+k_{A b o t} x_{r}=P K_{T} i \\
& m_{E} \ddot{x_{r}}+b_{E} \dot{x_{r}}+k_{A b o t} x_{r}=f_{E} \\
& Z_{A b o t}(s)=m_{E} s^{2}+b_{E} s+k_{A b o t}
\end{aligned}
$$

Here, $x_{r}$ is rod displacement, $m_{E}$ and $b_{E}$ were defined as actuator output equivalent mass and damping, respectively, and $f_{E}$ was command equivalent output force. When coupled with the human ankle, the total impedance was represented as eq. (3).

$$
\frac{f_{E}(s)}{x_{r}(s)}=m_{E} s^{2}+b_{E} s+k_{\text {Abot }}+Z_{\text {Ankle }}(s)
$$

Thus ankle mechanical impedance can be calculated by subtracting the actuator impedance $\left(Z_{A b o t}\right)$ from the total impedance (4).

$$
Z_{\text {Ankle }}(s)=\frac{f_{E}(s)}{\mathrm{x}_{\mathrm{r}}(\mathrm{s})}-Z_{\text {Abot }}(s)
$$

To estimate the total impedance and the actuator impedance in the IE and DP directions, two uncorrelated pseudorandom command voltages with bandwidth of $100 \mathrm{~Hz}$ were applied to each actuator to produce random perturbations, and corresponding displacements were recorded. From the time history of these data, multi-variable impedance was estimated using a stochastic identification method [12, 14]. Estimated results in actuator coordinates were transformed to joint coordinates using the nonlinear actuator kinematics [15].

\section{ANKLE IMPEDANCE IDENTIFICATION RESULTS}

EMG amplitudes during perturbation were much less than the levels when muscles were active (less than $5 \%$ of maximum voluntary contraction level).

As expected from the bandwidth of the applied perturbation $(100 \mathrm{~Hz})$, coherence was high up to $50 \mathrm{~Hz}(>0.8)$. Representative coherence plots of the actuator and the actuator plus ankle measurements are presented (Fig.3).
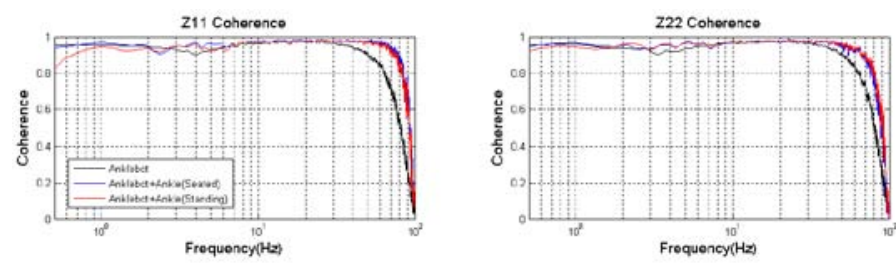

Fig.3. Coherence plot in DP and IE directions (Black: Anklebot actuator alone, Blue: Anklebot actuator coupled with the ankle, seated, Red: Anklebot actuator coupled with the ankle, standing)

Average impedance Bode plots for all 6 subjects up to $50 \mathrm{~Hz}$ are presented in (Fig. 4 and Fig.5). 

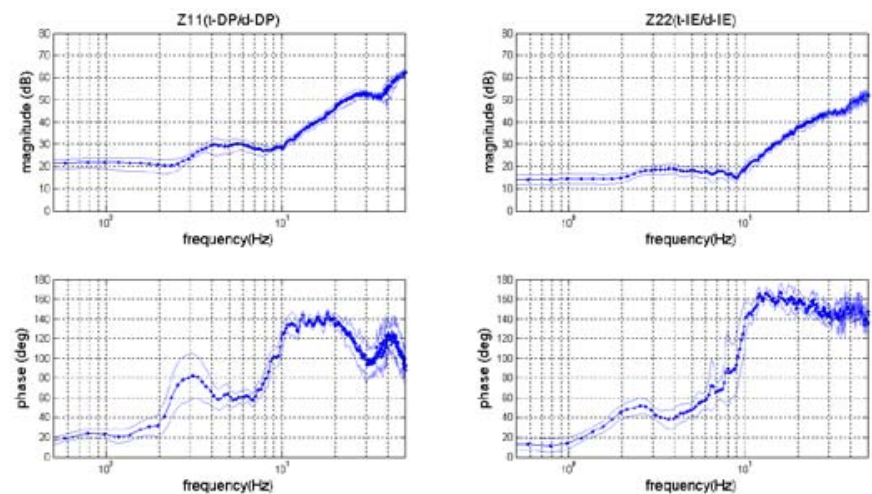

Fig.4. Ankle impedance estimate in a seated position (Left: sagittal plane (DP), Right: frontal (IE), Blue: mean of all subjects, Light blue: mean \pm 1 standard deviation (SD))

In both the seated and standing positions the frequency region over $9 \sim 10 \mathrm{~Hz}$, response was more or less consistent with inertia-dominated behavior (magnitude increased at $\sim 40 \mathrm{~dB} / \mathrm{dec}$ ). In addition, resonant and anti-resonant behavior was observed in the high frequency region between 20 to $30 \mathrm{~Hz}$. In the low frequency region $(<2 \mathrm{~Hz})$ stiffness was dominant with a magnitude slope close to zero.

However, in the seated position, the magnitude response in the mid frequency region, from about $2 \sim 4 \mathrm{~Hz}$ up to $9 \sim 10 \mathrm{~Hz}$, was markedly different from a simple $2^{\text {nd }}$ order system. Impedance magnitude in this mid frequency region was $2 \sim 3$ times higher than in the low frequency region. The phase response in this mid frequency region showed a substantial phase lead followed by a subsequent phase lag.
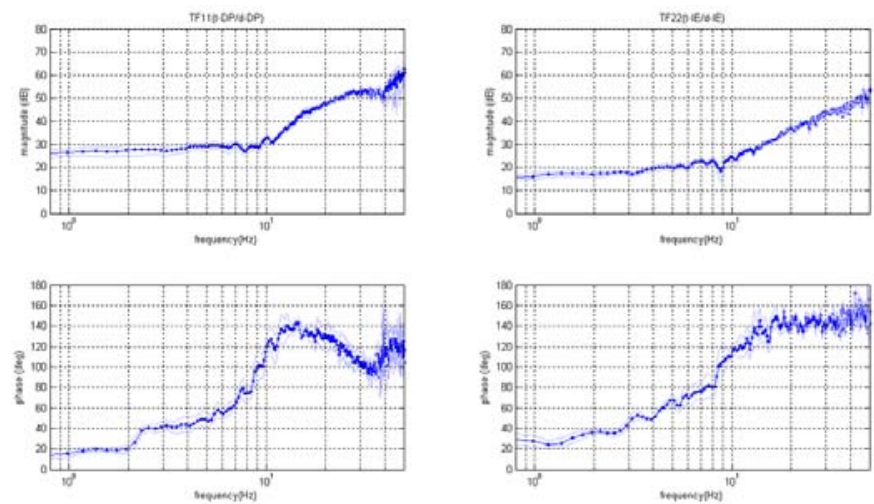

Fig.5. Ankle impedance estimation in a standing position

Ankle impedance in the standing position, was significantly different from the seated position. In general it became closer to a $2^{\text {nd }}$ order system although deviations in the mid frequency region still can be seen. Another interesting change was that the impedance magnitude in the low frequency region in the standing position was higher than in the seated. These two characteristics were consistent across all 6 subjects.

\section{ANKLE IMPEDANCE MATHEMATICAL MODEL}

A quantitative mathematical model describing the identified ankle impedance was developed. In this study, attention was focused on a frequency range less than $20 \mathrm{~Hz}$, with special interest in the low and mid frequency region (up to $10 \mathrm{~Hz}$ ). We started modeling with the well known Hill muscle model which consists of a series elastic element (often associated with the muscle tendon) connected to a parallel combination of an ideal force source, a viscous damper and an elastic element. Force generators $\left(f_{o n}, f_{o g}\right)$ are set as zero since this study was performed on the relaxed muscle conditions. However, a Hill model coupled with a rotational inertia was unable to represent the fast phase transition in the midfrequency region.

Because a fast phase increase followed by a phase lag can be obtained from a resonant behavior, we modified the Hill muscle model by adding a mass to the junction between muscle and tendon elements. An antagonistic pair of these model muscles coupled through a constant moment arm to a foot inertia (Fig.6) generated a $6^{\text {th }}$ order system eq. (5).

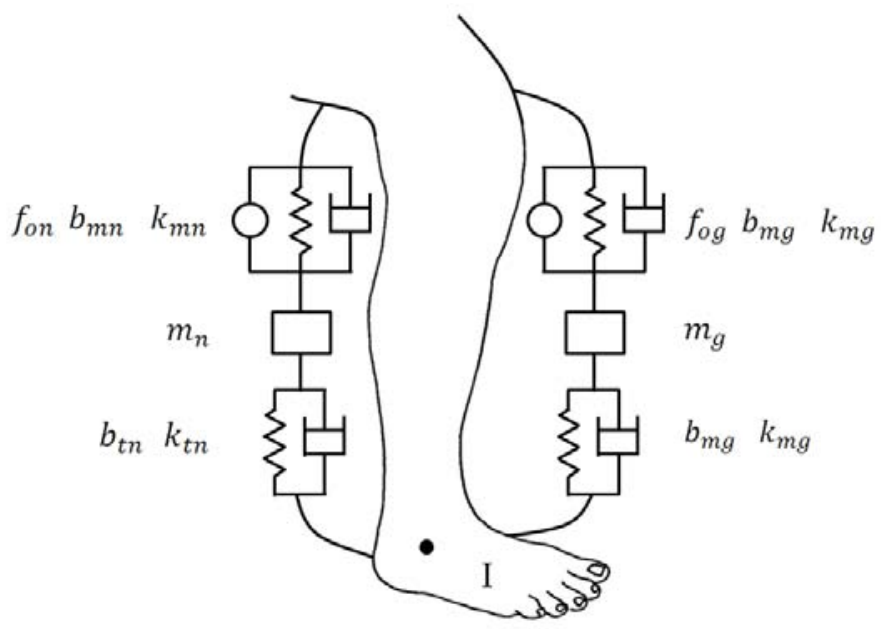

Fig. 6. The ankle with modified Hill model muscles. Subscripts $\mathrm{g}$ and $\mathrm{n}$ denote agonist and antagonist muscles, respectively. $\left(f_{o}\right.$ : force source, $k_{m}, b_{m}$ : elastic and viscous element of a muscle, $k_{t}, b_{t}$ : elastic and viscous element of a tendon, $m$ : inserted mass, $r$ : moment arm, $I$ : foot inertia)

$$
\begin{aligned}
\frac{\tau_{n e t}(s)}{\theta(s)} & =r_{g}{ }^{2}\left\{\frac{m_{g} b_{t g} s^{3}+\left(m_{g} k_{t g}+b_{m g} b_{t g}\right) s^{2}+\left(b_{m g} k_{t g}+b_{t g} k_{m g}\right) s+k_{m g} k_{t g}}{m_{g} s^{2}+\left(b_{m g}+b_{t g}\right) s+\left(k_{m g}+k_{t g}\right)}\right\} \\
& +r_{n}{ }^{2}\left\{\frac{m_{n} b_{t n} s^{3}+\left(m_{n} k_{t n}+b_{m n} b_{t n}\right) s^{2}+\left(b_{m n} k_{2 n}+b_{t n} k_{m n}\right) s+k_{m n} k_{t n}}{m_{n} s^{2}+\left(b_{m n}+b_{t n}\right) s+\left(k_{m n}+k_{t n}\right)}\right\}+I s^{2}
\end{aligned}
$$

When a single muscle model was used rather than an antagonistic pair, the model generated a simpler $4^{\text {th }}$ order system eq. (6). Here subscript $e$ denotes effective elements.

$\frac{\tau_{n e t}(s)}{\theta(s)}=r^{2}\left\{\frac{m_{e} b_{t e} s^{3}+\left(m_{e} k_{t e}+b_{m e} b_{t e}\right) s^{2}+\left(b_{m e} k_{t e}+b_{t e} k_{m e}\right) s+k_{m e} k_{t e}}{m_{e} s^{2}+\left(b_{m e}+b_{t e}\right) s+\left(k_{m e}+k_{t e}\right)}\right\}+1 s^{2}$ 
The measured ankle impedance was fit to $6^{\text {th }}, 4^{\text {th }}$ and $2^{\text {nd }}$ order models. For the $6^{\text {th }}$ and $4^{\text {th }}$ order models, an unconstrained nonlinear optimization method (Nelder-Mead simplex method: MATLAB's fminsearch function) [16] was used, and the mean of magnitude difference up to $20 \mathrm{~Hz}$ between the model and the measurement was minimized. In current study, phase response was not considered for optimization process, since more accurate estimates of the magnitude response was our major interest. For the $2^{\text {nd }}$ order model, its parameters were determined by fitting the low and high frequency regions, which correspond to stiffness and inertia, respectively.

Modeling error and goodness of fit were calculated to evaluate model performance. In detail, modeling error was defined as the mean magnitude difference between the model and the measurement in the low and mid frequency region (up to $10 \mathrm{~Hz})$. Percentage variance accounted for (\%VAF) between the model and the identification result was computed to measure how well the model described the identified result (7).

$$
\% \operatorname{VAF}=100 \times\left(1-\frac{\operatorname{var}(\mathrm{z}-\hat{\mathrm{z}})}{\operatorname{var}(\mathrm{z})}\right)
$$

where $\mathrm{z}$ is the frequency response magnitude of the measurement, $\hat{\mathrm{z}}$ of the model, and $\operatorname{var}(\mathrm{x})$ is an estimate of the variance of the random variable $\mathrm{x}$.

Using these two performance measures, $4^{\text {th }}$ and $6^{\text {th }}$ order models were quantitatively compared with the $2^{\text {nd }}$ order model.

\section{ANKLE IMPEDANCE MODELING RESULTS}

In the seated position (Fig.7) the $6^{\text {th }}$ order model competently represented relaxed ankle impedance in both the DP and IE directions. Although its modeling error was slightly larger than the $6^{\text {th }}$ order model (Table.1), a $4^{\text {th }}$ order model competently represented important transitions in the response up to $20 \mathrm{~Hz}$. On the other hand, the $2^{\text {nd }}$ order model resulted in substantial deviations in the mid frequency region for both magnitude and phase response.
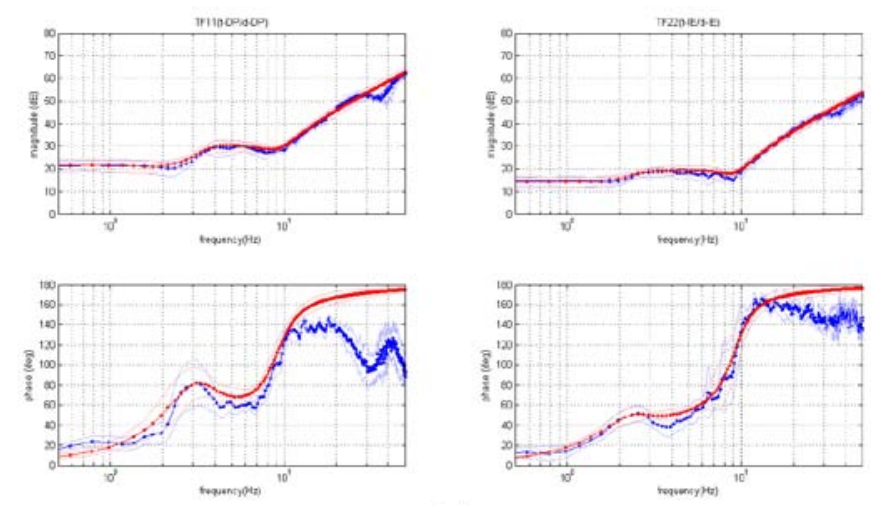

(a)
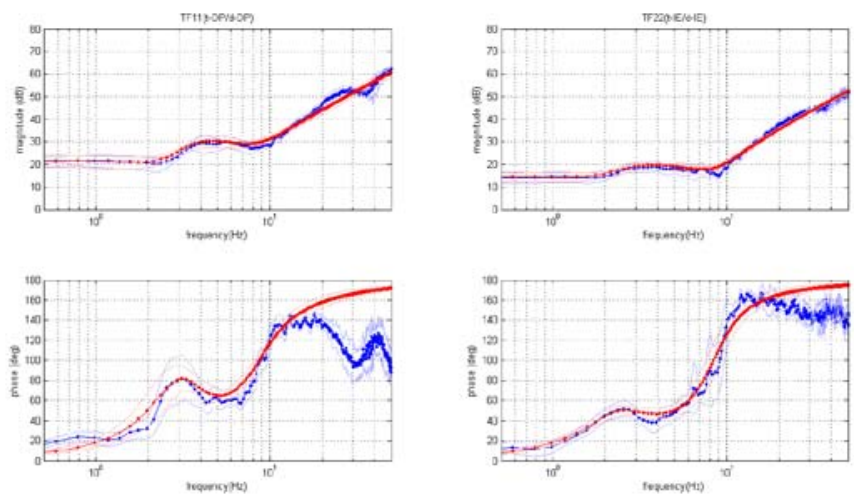

(b)
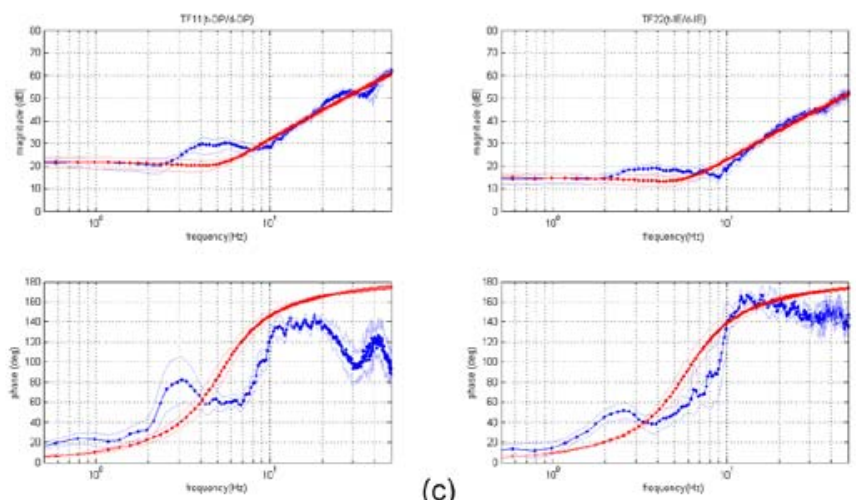

(c)

Fig.7. Modeling relaxed ankle impedance in the seated position (Red: Model, Blue: Estimation, Pale lines: Mean \pm 1 STD) $-(a): 6^{\text {th }}$ order model, (b): $4^{\text {th }}$ order model, (c): $2^{\text {nd }}$ order model

In the standing position, considering the slighter deviations from $2^{\text {nd }}$ order behavior in the mid-frequency region, the identified impedance was fit with a $4^{\text {th }}$ order model and compared with a $2^{\text {nd }}$ order model (Fig.8).

In the standing position, the $4^{\text {th }}$ order model competently represented the data with a modeling error comparable to the $6^{\text {th }}$ order model in the seated position (Table 1). As in the case of the seated position, the $2^{\text {nd }}$ order model was unable to represent the mid frequency region accurately even in the standing position.

Table.1. Quantification of modeling error

\begin{tabular}{cccc}
\hline \hline $\begin{array}{c}\text { Seated } \\
\text { Position }\end{array}$ & $\begin{array}{c}2^{\text {nd }} \text { order } \\
\text { Model }\end{array}$ & $\begin{array}{c}4^{\text {th }} \text { order } \\
\text { Model }\end{array}$ & $\begin{array}{c}6^{\text {th }} \text { order } \\
\text { Model }\end{array}$ \\
\hline$Z 11$ (DP) & $11.26(3.64)$ & $2.32(0.29)$ & $2.03(0.26)$ \\
$Z 22$ (IE) & $2.80(0.62)$ & $0.64(0.19)$ & $0.56(0.19)$ \\
\hline \hline Standing & $2^{\text {nd }}$ order & $4^{\text {th }}$ order & - \\
Position & Model & Model & - \\
\hline$Z 11$ (DP) & $4.77(1.57)$ & $2.03(0.38)$ & - \\
$Z 22($ IE) & $2.58(0.69)$ & $0.72(0.14)$ & - \\
\hline \hline
\end{tabular}

( ): Standard deviation, Unit: [Nm/rad] 

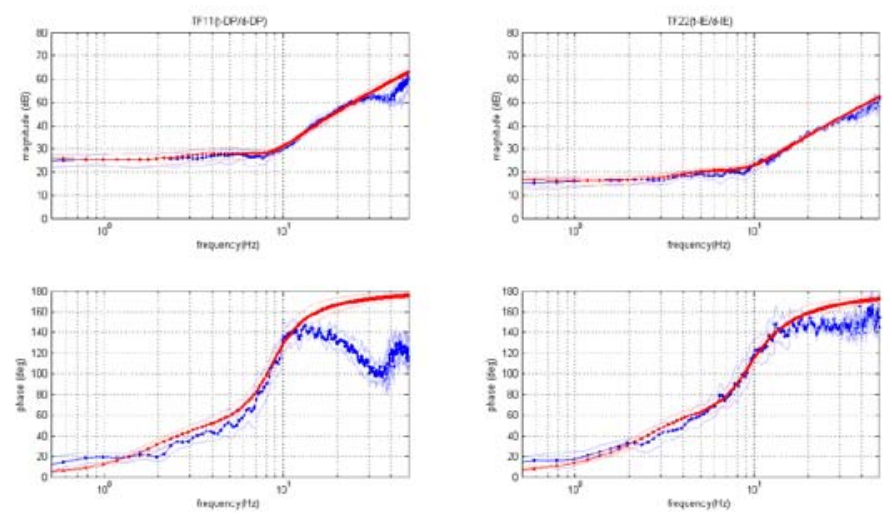

(a)
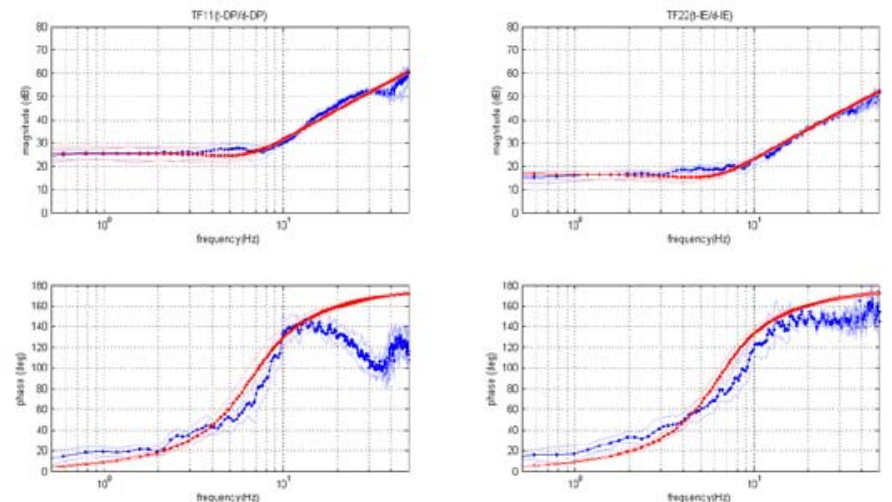

(b)

Fig.8. Modeling relaxed ankle impedance in the standing position (Red: Model, Blue: Estimation, Pale lines: Mean \pm 1 STD) $-(a): 4^{\text {th }}$ order model, (b): $2^{\text {nd }}$ order model

In the seated position, the mean \% VAF of all subjects was higher than $75 \%$ and $80 \%$ with the $4^{\text {th }}$ order and $6^{\text {th }}$ order models, respectively. In the standing position, this value was higher than $80 \%$ with the $4^{\text {th }}$ order model (Table 2 ).

Table.2. Quantification of \% VAF

\begin{tabular}{cccc}
\hline \hline $\begin{array}{c}\text { Seated } \\
\text { Position }\end{array}$ & $\begin{array}{c}2^{\text {nd }} \text { order } \\
\text { Model }\end{array}$ & $\begin{array}{c}4^{\text {th }} \text { order } \\
\text { Model }\end{array}$ & $\begin{array}{c}6^{\text {th }} \text { order } \\
\text { Model }\end{array}$ \\
\hline$Z 11$ (DP) & $52.02(5.64)$ & $79.85(2.67)$ & $87.03(2.89)$ \\
$Z 22(\mathrm{IE})$ & $53.99(9.15)$ & $76.25(4.81)$ & $81.75(4.26)$ \\
\hline \hline Standing & $2^{\text {nd }}$ order & $4^{\text {th }}$ order & - \\
Position & Model & Model & - \\
\hline$Z 11(\mathrm{DP})$ & $75.74(4.12)$ & $82.07(3.40)$ & - \\
$Z 22(\mathrm{IE})$ & $65.15(6.48)$ & $81.67(1.53)$ & - \\
\hline \hline
\end{tabular}

( ): Standard deviation

\section{DISCUSSION}

Dynamic ankle mechanical impedance with relaxed muscles was successfully identified using a multi-variable stochastic identification method. Unlike the previous work by Rastgaar et al. [12], the estimation method subtracted actuator impedance from the total impedance rather than actuator and shoe together. This yielded higher repeatability and higher coherence from the lowest frequency region, less than $1 \mathrm{~Hz}$, to the high frequency region, up to $50 \mathrm{~Hz}$. As a result, subtle changes in IE impedance can be observed, which were unavailable with the previous method.

From the identification results, we found several interesting points. First, ankle impedance changes depending on lower limb posture. The mid frequency response in the seated position was clearly different from the standing position. This difference was observed across all 6 subjects. It can be explained with the property of gastrocnemius, which is a biarticular muscle, thus stretched more in the standing position than in the seated position.

This change of ankle impedance between the standing and seated positions may be important, because those two knee postures are common in our daily life such as level walking, stair ascent/descent, driving, etc. Second, the patterns of frequency response changes were qualitatively similar for both DP and IE impedance. Third, IE impedance was always lower than DP impedance, confirming previous work $[12,15]$.

Ankle impedance in the seated position showed clear deviations from the simple $2^{\text {nd }}$ order model which has been assumed by many other research groups. The mid frequency impedance exceeded the low frequency impedance by more than a factor of 3 and 2 in the DP and IE directions, respectively. Thus, a $2^{\text {nd }}$ order approximation was not competent to accurately describe the mid frequency dynamic behavior of the ankle. Although ankle impedance in the standing position more closely resembled a $2^{\text {nd }}$ order system, both DP and IE impedance still exhibited a transition behavior in the mid frequency region. In average, the mid frequency impedance is higher than the low frequency impedance by about $25 \%$ and $50 \%$ in the DP and IE directions, respectively.

When coupled with the foot inertia, the modified Hill model having a mass between the junction of muscle and tendon elements successfully captured the dynamic behavior of ankle impedance up to $20 \mathrm{~Hz}$ both in the seated and standing position. Constant moment arms were assumed based on the information from [17] that both dorsiflexor and plantarflexor moment arms change less than $10 \%$ in the experimental conditions used here (mean displacement amplitude due to the random perturbation was less than $7^{\circ}$ ). On average, the $6^{\text {th }}$ order model derived from an antagonistic pair of modified Hill muscle models coupled with the foot inertia explained dynamic ankle impedance more accurately than the $4^{\text {th }}$ order model. However, the modeling error of the $4^{\text {th }}$ order was still good, comparable to the result of $6^{\text {th }}$ order model. Impedance in the standing position was well described with a $4^{\text {th }}$ order model. The modeling error in this case was not statistically significantly different $(\mathrm{p}>0.05)$ from the result with a $6^{\text {th }}$ order model in the seated position.

The model qualitatively represented the major phase changes up to $15 \mathrm{~Hz}$, but with some error. This error could be attributed to two reasons. First, the optimization method used 
here minimized only magnitude errors between the model and the measurement. If the objective function was changed to the mean error between the complex-valued impedances of the model and the measurement, phase error might be improved. Second, a resonant behavior in the high frequency region was another source of phase error. In the current models, this behavior was ignored. However, large phase errors in the high frequency region still can affect the mid and low frequency region, since the phase effects of a pole or zero may be significant at frequencies a decade higher or lower. For example, an $8^{\text {th }}$ order model may be justified by splitting the foot inertia in two and adding an elastic element between the two pieces. If this higher-order model is used to fit the observations, error may be improved in the low and mid frequency region as well as in the high frequency region over $20 \mathrm{~Hz}$. From the above two explanations, we can see that there are two distinct tradeoffs, between magnitude and phase error, and accuracy and complexity in modeling dynamic ankle impedance.

Currently we are working on mapping the optimized zero/pole pairs to the modified Hill model parameters. This will allow us to test whether these parameters are reasonably consistent with known biomechanical data. If successful, we may be able to use dynamic impedance measurements to identify abnormal muscle properties, which are common sequelae of neurological disorders such as stroke or Cerebral Palsy [18].

There is another issue of using vibratory perturbation in experiments. Although EMG amplitudes during perturbation were much less than the levels when muscles were active, they were still statistically significantly different from the ones during rest period $(p<0.05)$. As known from the previous study [19], vibratory motions at the ankle can evoke stretch reflex, which may affect ankle impedance. Further study is needed to identify the contribution of this reflex component to ankle impedance.

In future work, we plan to estimate dynamic ankle mechanical impedance with active muscles including antagonist muscle co-contraction.

\section{ACKNOWLEDGMENTS}

Funded by Toyota Motor Corporation's Partner Robot Division. H. Lee is supported by Samsung Scholarship

\section{REFERENCES}

[1] P. DeVita, J. Helseth, and T. Hortobagyi, 2007. "Muscles do more positive than negative work in human locomotion", $\mathrm{J}$. Experimental Biology, 210(19), pp.3361-3373

[2] P.Procter, 1982. “Ankle joint biomechanics", J.Biomechanics, 15(9), pp.627-634

[3] J.Dul and G.Johnson, 1985. "A kinematic model of the human ankle”, J.Biomechanics, 7(2), pp.137-143
[4] A.Singh, K.Starkweather, A.Hollister, S.Jatana, and A.Lupichuk, 1992. "Kinematics of the ankle: A hinge axis model", Foot \& Ankle, 13(8), pp. 439-446

[5] A.Leardini, J.O'Connor, F.Catani, and S.Giannini, 1999. "A geometric model of the human ankle joint", J.Biomechanics, 32, pp.585-591

[6] G.Gottlieb and G.Agarwal, 1978. "Dependence of human ankle compliance on joint angle", J.Biomechanics, 11(4), pp.177181

[7] I.Hunter and R.Kearney, 1982. "Dynamics of human ankle stiffness: variation with mean ankle torque", J.Biomechanics 15(10), pp.747-752.

[8] R.Kearney and I.Hunter, 1982. "Dynamics of human ankle stiffness: variation with displacement amplitude". J.Biomechanics 15(10), pp.753-756.

[9] P.Weiss, R.Kearney, and I.Hunter, 1986. "Position dependence of ankle joint dynamics- I. Passive mechanics", J.Biomechanics 19(9), pp.727-735.

[10] P.Weiss, R.Kearney, and I.Hunter, 1986. "Position dependence of ankle joint dynamics- $\amalg$. Active mechanics", J.Biomechanics 19(9), pp.737-751.

[11] S.Zinder, K.Granata, D.Padua, and B.Gansneder, 2007. "Validity and Reliability of a New In Vivo Ankle Stiffness Measurement Device”, J.Biomechanics, 40(2), pp.463-467.

[12] M.Rastgaar, P.Ho, H.Lee, H.Krebs, and N.Hogan, 2009. "Stochastic estimation of multi-variable human ankle mechanical impedance", In Proc. ASME Dynamic Systems and Control Conference, pp45-47.

[13] A.Roy, H.Krebs, D.Williams, C.Bever, L.Forrester, R.Macko, and N.Hogan, 2009. "Robot-aided Neurorehabilitation: A Robot for Ankle Rehabilitation", IEEE Trans. on Robotics, 25(3), pp. 569582.

[14] J.Bendat and A.Piersol, 2010. "Random Data: Analysis and Measurement Procedures", 4th edition, Wiley

[15]H.Lee, P.Ho, M.Rastgaar, H.Krebs, and N.Hogan, 2011. "Multivariable Static Ankle Mechanical Impedance with Relaxed Muscles",J.Biomechanics,(DOI: 0.1016/j.jbiomech.2011.04.028)

[16] J.Lagarias, J.Reeds, M.Wright, and P.Wright, 1998. “Convergence Properties of the Nelder-Mead Simplex Method in Low Dimensions", SIAM Journal of Optimization, 9(1), pp. 112-147.

[17] S.Rugg, R.Gregor, B.Mandelbaum, and L.Chiu, 1990. "In vivo moment arm calculations at the ankle using magnetic resonance imaging (MRI)", J.Biomechanics 23(5), pp.495-501.

[18] A.Roy, H.Krebs, C.Bever, L.Forrester, R.Macko, and N.Hogan, 2011. "Measurement of Passive Ankle Stiffness in Subjects with Chronic Hemiparesis using a Novel Ankle Robot", J.Neurophysiology, article in press

[19] R.Ritzmann, A.Kramer, M.Gruber, A.Gollhofer, and W.Taube, 2010. "EMG activity during whole body vibration: motion artifacts or stretch reflexes?", European Journal of Applied Physiology 110 (1), 143-151 